\title{
A cross-categorial definite determiner: Evidence from Ga (Kwa)*
}

\author{
Agata Renans \\ Universität Potsdam
}

\begin{abstract}
This paper contributes to the growing body of evidence that in a crosslinguistic perspective there are definite descriptions of categories other than NPs. Based on novel data from $\mathrm{Ga}$, an under-researched language spoken in Ghana, the paper argues that the definite determiner $l \varepsilon$ marks overtly familiarity and uniqueness in both the nominal and the verbal domain. When $l \varepsilon$ attaches to the VP, it marks an event as definite. The paper shows that definiteness in the verbal domain not only exists but also has the same properties as in the nominal domain, pointing to further parallelism between both.
\end{abstract}

Keywords: cross-categorial definite determiners, fieldwork semantics, Ga language

\section{Introduction}

It has been observed in the literature that in a cross-linguistic perspective languages can mark other categories than NPs as definite. For example, Baker \& Travis (1997) argue that mood prefixes in Mohawk mark the verbal equivalent of (in)definiteness, Larson (2003) analyzes final clausal definite determiners in Fon and Haitian Creole as definite adverbs, and Grubic (2015) proposes analyzing the Ngamo background marker $i /=y e$ as a definiteness marker of topic situations.

Even though the idea that languages have definite descriptions in domains other than the nominal one is not new, there are at least two important points that make the Ga definite determiner $l \varepsilon$ interesting from a theoretical point of view. First, it has the same overt form in both the nominal and the verbal domain and shows exactly the same properties in both. Second, as a consequence it interacts with the aspectual and evidential information of the sentence; that is, clefted imperfective sentences with $l \varepsilon$ attached to the VP invariably convey a progressive aspectual reference and

* I would like to thank Judith Tonhauser, Malte Zimmermann, Mira Grubic, Anne Mucha, Radek Šimík, Marta Wierzba, Joseph P. DeVeaugh-Geiss and the participants of SALT 26 for helpful discussions on various parts of this paper. I also gratefully acknowledge financial support from the German Research Foundation (DFG) as part of the Collaborative Research Centre (SFB) 632 'Information Structure,' Project A5. All errors are mine. 
require direct evidential contexts in order to be felicitously uttered, as demonstrated in $(1 \mathrm{a}-\mathrm{d}){ }^{1}$

\section{(1) Kòfí nì sèlè-ó $\quad \mathbf{l} \boldsymbol{\varepsilon}$.}

\section{Kofi PRT swim-IMPF DET}

'It is Kofi who is swimming.'

a. progressive context: Tom and his family (wife, two sons, and two daughters) are on the beach. Tom and his wife can see a swimming child.

$\Rightarrow$ Tom can utter (1) in this context

b. habitual context: Tom's youngest son and daughters do not like swimming and they do not do it, but his oldest son, Kofi, loves swimming and he does it regularly. $\Rightarrow$ Tom cannot utter (1) in this context

c. direct evidence context: Tom and his family (wife, two sons, and two daughters) are on the beach. Tom can see that his youngest son and two daughters are playing with sand and his oldest son, Kofi, is swimming.

$\Rightarrow$ Tom can utter (1) in this context

d. indirect evidence context: The same as before but this time Tom cannot see his oldest son, but the younger one told him that Kofi was in the process of swimming.

$\Rightarrow$ Tom cannot utter (1) in this context

That the progressive and evidential interpretation in (1) is caused by the definite determiner $l \varepsilon$ is suggested by the observation that sentences without VP $l \varepsilon$ obtain a habitual but not a progressive interpretation, as demonstrated in (2), and they do not put any constraints on their evidential interpretation.

(2) Kòfí nì sèlè-ó.

Kofi PRT swim-IMPF

'It is Kofi who swims.'

a. progressive context: Tom and his family (wife, two sons, and two daughters) are on the beach. Tom and his wife can see a swimming child.

$\Rightarrow$ Tom cannot utter (2) in this context

b. habitual context: Tom's youngest son and daughters do not like swimming and they do not do it, but his oldest son, Kofi, loves swimming and he does it regularly. $\Rightarrow$ Tom can utter (2) in this context

1 The glosses used in this paper: DET $=$ determiner; $1=$ First person; $2=$ Second person; $3=$ Third person; $\mathrm{PRT}=$ particle; $\mathrm{NOM}=$ nominalizer; $\mathrm{NEG}=$ negation $; \mathrm{COMPL}=$ complementizer; $\mathrm{REL}=$ relativizer; $\mathrm{IMPF}=$ imperfective; $\mathrm{PROG}=$ progressive; $\mathrm{IMP}=$ imperative. An example marked with '\#' means that the example was judged as unacceptable in the given context and I hypothesize that it is for semantic or pragmatic reasons. Examples without any diacritics were judged as acceptable in the given context. 
The goal of this paper is two-fold: First, it provides novel empirical evidence that cross-categorial definite determiners are attested in natural language. Second, it gives a formal semantic analysis. In particular, I argue that both in the nominal and the verbal domain the definite determiner $l \varepsilon$ encodes the information that a discourse referent, an event in the case of the verbal domain, is both familiar and unique in bearing the property in question. This, together with the imperfective aspectual reference conveyed by the marker $-\supset$, leads to the invariable progressive and direct evidential interpretation of (1).

The structure of the paper is as follows. Section 2 gives an overview of the variety of ways used to convey a definite interpretation in Ga. One of them, i.e., the particle $l \varepsilon$, is discussed in detail in Section 3. This section presents the main data providing empirical evidence that $l \varepsilon$ is a cross-categorial definite determiner marking definiteness in both the nominal and the verbal domain. Its formal semantic analysis is presented in Section 4. Subsequently, Section 5 discusses the predictions of the analysis, i.e., the interaction with the aspectual and evidential interpretation of the sentence. Section 6, in turn, considers further research directions and briefly discusses the semantic properties of another cross-categorial definite determiner in Ga: $n \varepsilon \varepsilon$. Section 7 concludes.

Before I dive into the discussion of definiteness in $\mathrm{Ga}$, let me give some information on the Ga language itself, the language consultants, and the methodology used. $\mathrm{Ga}(\mathrm{Kwa})$ is an under-researched Ghanaian language spoken in The Greater Accra Region by ca. 600,000 speakers. Its basic word order is SVO and it has two tones: Low and High. All the data stem from the author's fieldwork with six Ga native speakers in Accra in 2014 and 2016 and one Ga native speaker in Berlin in 2015 (four women, two men). All of the language consultants grew up in a Ga-speaking community. Five of the native speakers consulted in Accra were students at the time of conducting the fieldwork, one of them with a background in linguistics. The methodology follows Matthewson 2004 and the tasks comprised mostly of acceptability judgment tasks in the given context.

\section{Definiteness in Ga}

It has been proposed in the literature that definite determiners encode uniqueness of the discourse referent, its existence, its familiarity, or a subset thereof. Following Frege (1892); Heim \& Kratzer (1998); Schwarz (2009); Elbourne (2013), among others, definite determiners were analyzed as encoding both uniqueness and existence inferences as presuppositions. On the approach labeled as Weak-Fregean by Coppock \& Beaver (2015), uniqueness is presupposed but the existence inference is not encoded by the definite determiner, and under a Russellian (1905) approach, both uniqueness and existence are asserted. By contrast, Heim (1982); Szabó (2000, 
2003), and Roberts (2003) propose analyzing definite determiners in terms of familiarity defined in various ways. ${ }^{2}$ Moreover, Barlew (2014) argues that the Bulu definite determiner -tè encodes along with uniqueness salience of the discourse referent, defined in terms of attention capture.

Looking at $\mathrm{Ga}$, a definite interpretation can be conveyed by different means which differ with respect to the meaning expressed by them. It seems that whereas the definite determiners $l \varepsilon$ and $n \varepsilon \varepsilon$ encode both uniqueness and familiarity of the discourse referent, bare nouns, which allow for either definite or indefinite interpretations, encode solely its uniqueness. ${ }^{3}$ That bare NPs can convey a definite interpretation is presented below in (3), which shows that they are acceptable when the NP referent is unique. At the same time, bare NPs are not acceptable in (4). It seems that this is the case because there was more than one town elder at the celebration; i.e., there was not a unique town elder at the celebration.

(3) context: There was a Ghanaian national day yesterday and there were a lot of celebrations in Accra which were visited by one president and many town elders:

Mì-nà màỳhíènyìćló.

1 SG-see president

'I saw the president.'

(4) context: There were five town elders at the celebration. We've talked about one of them. I say:

\#Mì-nà màỳ ònúkpá.

1SG-see town elder

intended: 'I saw the town elder.'

By contrast, the distribution of the definite determiner $n \varepsilon \varepsilon$ is restricted to contexts in which the referent NP is both unique in bearing the property in question and familiar to the speaker as well as to the hearer. ${ }^{4}$ A piece of data suggesting this kind of empirical generalization is given in (5):.$^{5}$

2 Note, however, that Roberts (2003) proposes that definites encode both familiarity and the informational uniqueness of the discourse referent.

3 For empirical evidence that bare NPs in Ga allow for indefinite interpretation, see Renans 2015.

4 One question is: What is the relation between the definite determiner $n \varepsilon \varepsilon$ and the demonstrative $n \varepsilon$ ? Preliminary data suggest that $n \varepsilon \varepsilon$ is not a demonstrative, but more fieldwork on the semantics of $n \varepsilon \varepsilon$ and $n \varepsilon$ must be conducted to warrant definite conclusions regarding the differences and similarities in their semantics.

5 The test in (5) follows the examples in Arkoh \& Matthewson 2013. 
A cross-categorial definite determiner

(5) context: Nardu visits her friend Ama. Ama is cooking banku and explains to Nardu that she bought a very fairly priced cassava on the market yesterday. The unused cassava is in the basket. While preparing the food, it turns out that Ama needs more cassava. She says:

Nàrdù kè dùàdé nec ní yoo kèǹtéń le mlì a-bà.

Nardu bring 1 cassava DET REL BE basket DET inside IMP-bring2

'Nardu, bring the cassava that is in the basket.'

Note that $n \varepsilon \varepsilon$ is not acceptable in a context in which Nardu (the hearer) does not know about the cassava. Whereas the precise formal analysis of the definite interpretation of bare NPs and the definite determiner $n \varepsilon \varepsilon$ has to await another occasion, in this paper I concentrate on the semantics of the definite determiner $l \varepsilon{ }^{6,7}$

I claim that $l \varepsilon$ encodes the information that a discourse referent is unique in bearing the property in question and familiar. A taxonomy of familiarity (Roberts 2003) is presented in (6):

Taxonomy of familiarity:

a. strong familiarity: the NP has as antecedent a discourse referent introduced via the utterance of a (usually) preceding NP

b. weak familiarity:

i. the entity referred to is perceptually accessible to the interlocutors

ii. the entity referred to is globally familiar in the general culture or at least among the participants in the discourse, although not mentioned in the immediate discourse

iii.introduction of the NP's discourse referent is licensed solely by contextual existence entailments

iv.weak familiarity is guaranteed by giving a functional interpretation to the definite description (which function may have to be accommodated with the intended argument(s) both familiar and highly salient (Bridging))

(Roberts 2003: 304)

In what follows, I argue that the felicitous use of $l \varepsilon$ requires a discourse referent to be either strongly or weakly familar; i.e., they exhibit various kinds of familiarity listed in (6).

6 Note that the particle $l \varepsilon$ comes in two forms: as a low tone $l \grave{\varepsilon}$, which is a third person singular pronoun, and tonally unspecified $l \varepsilon$ with a floating high tone which docks onto the preceding syllable (Dakubu 1992). Tonally unspecified $l \varepsilon$ attaches to various elements; e.g., NPs, VPs, temporal subordinate clauses, relative clauses, and antecedents of conditionals. Moreover, it functions as a topic marker (Renans 2016). In this paper, though, I concentrate solely on the use of $l \varepsilon$ as a definite determiner. 7 See also Dakubu 1992 and Dakubu 2005 for previous analyses of $l \varepsilon$. 
Renans

\section{The definite determiner $l \varepsilon$}

\subsection{NP le}

Example (7) shows that $l \varepsilon$ cannot be used at the beginning of the conversation, suggesting the analysis of $l \varepsilon$ as requiring a familiar discourse referent. It is in line with the observation that $l \varepsilon$ can be felicitously used in the second sentence of (7), in which a discourse referent wolo 'book' is strongly familiar due to the antecedent NP wolo in the first sentence:

(7) context: beginning of the conversation

$$
\begin{aligned}
& \text { Mì-káne wòlo (\#le) nyè. Wòlo \#(le) è-yò } \quad \text { wàà. } \\
& 1 \text { SG-read book DET yesterday book DET 3SG-be.tasty very } \\
& \text { 'I read a book yesterday. The book was interesting.' }
\end{aligned}
$$

The definite determiner $l \varepsilon$ can also be used when the discourse referent is not strongly but weakly familiar, e.g., due to perceptual evidence or general knowledge, as demonstrated in (8) and (9), respectively:

context: I see that a boy is kicking John. I say:

Gbéke nùú le mì̀-bútu John.

child man DET PROG-kick John

'The boy is kicking John.'

(9) context: There was a Ghanaian national day yesterday and there was a big celebration ceremony in Accra which was visited by the Ghanaian president and town elders. I met my friend. We talked about how beautiful the celebration was (but we didn't talk about who was there). He asked me whether I saw any famous person. I reply:

$$
\begin{aligned}
& \text { Mì-nà màỳhíènyìćló le. } \\
& 1 \text { SG-see president DET } \\
& \text { 'I saw the president.' }
\end{aligned}
$$

The determiner $l \varepsilon$ is also acceptable in bridging contexts in which the discourse referent has not been previously mentioned but it is familiar due to the relation between the discourse referent picked up by the definite determiner and the previously mentioned discourse referent, as in (10), where the first sentence sets the scene for the second one:

(10) Nardu he ataade fecfeo. Nikpelo le he-ee shika pii.

Nardu buy dress beautiful tailor DET take-NEG money many

'Nardu bought a beautiful dress. The tailor didn't take a lot of money.' 
A cross-categorial definite determiner

Conversely, example (11) shows that $l \varepsilon$ cannot be felicitously used when a discourse referent is unfamiliar:

(11) context: Kofi went to the market and bought several books we never talked about.

\#Kofi he woji le.

Kofi buy books DET

'Kofi bought the books.'

However, the familiarity of the discourse referent is not sufficient for $l \varepsilon$ to be felicitously used. Examples $(12-14)$ provide evidence that the discourse referent picked up by $l \varepsilon$ must not only be familiar but also unique in bearing the property in question. Consider (12). Since there is only one president, which in addition is familiar due to general knowledge, (12a) is acceptable in the context of (12). By contrast, the governors are neither unique nor familiar and thus (12b) is unacceptable in the context of (12).

(12) context: Yesterday was the Ghanaian national day and there were a lot of celebrations in Accra, which were visited by one president and many town elders.

a. Mì-nà màỳhíènyìćló le.

1SG-see governor DET

'I saw the president.'

b. \#Mì-nà màǹ ònúkpá le.

1SG-see town elder DET

'I saw the town elder.'

Importantly, (12b) becomes acceptable, if one of the town elders was discussed before, as in (13). However, it is still unacceptable if more than one elder was discussed, as illustrated in (14), supporting the idea that the discourse referent picked up by $l \varepsilon$ needs to be both familiar and unique in bearing the property in question. Note, however, that $l \varepsilon$ does not require a discourse referent to be unique in general but rather that the familiar discourse referent is unique, which comes down to Roberts's (2003) notion of informational uniqueness.

(13) context: There were five town elders at the celebrations. We've talked about one of them. $\Rightarrow(12 b)$ is acceptable in this context

(14) context: There were five town elders at the celebrations. We've talked about two of them. $\Rightarrow(12 b)$ is unacceptable in this context 
This view is also supported by the unacceptability of (15a) as the continuation of (15), providing additional evidence that the discourse referent picked up by $l \varepsilon$ must be informationally unique:

(15) Mì-káne wò-jì ényò nyè.

1SG-read book-PL two yesterday

'I read two books yesterday.'

a. \#Wòló le è-njò wànà

book DET 3SG-be.tasty very

'The book was interesting.'

Moreover, Barlew (2014) proposed another dimension, besides familiarity and uniqueness, along which the semantics of definite determiners differ, i.e., salience. He showed that the Bulu definite determiner -tè encodes uniqueness and salience defined in terms of attention capture; i.e., in order to felicitously use -tè the speaker 'needs to have (accurate) evidence that the addressee is attending to that antecedent' (Barlew 2014: 625). It predicts the acceptability of the target sentence (16b-i) in the context of (16a), in which the addressee's attention is captured by the sun due to the action of opening the window, and the unacceptability of (16b-i) in the context of (16b), in which the speaker does not have any evidence that the adressee's attention is captured by the sun. Whereas, these predicitons are borne out in Bulu, the Ga target sentence in (16b-i) is acceptable in both contexts suggesting that salience is not encoded by $l \varepsilon^{8}$

(16) a. context 1: Kofi is sitting on a bus when a man he does not know sits down beside him. The stranger opens the window shade on the bus, letting in sunlight and says (16b-i).

b. context 2: Kofi is sitting on a bus when a man he does not know sits down beside him. The stranger says (16b-i).

i. Hùlú le mì̀-kpé wàà jméné. sun DET PROG-shine strongly today

'The sun is bright today.'

$\Rightarrow$ The stranger can utter (16b-i) in both contexts

Summing up, NP $l \varepsilon$ encodes familiarity of the discourse referent and its uniqueness in bearing the property in question but not salience.

8 The test in (16) follows the examples in Barlew 2014. 
A cross-categorial definite determiner

\subsection{VP le}

The definite determiner $l \varepsilon$ attaches to VPs across all aspectual categories with the caveat that the sentence must be clefted. ${ }^{9}$ This is illustrated in $(17 \mathrm{a}, 18 \mathrm{a})$ and $(17 \mathrm{~b}, 18 \mathrm{~b})$ for the unmarked aspectual reference and sentences conveying imperfective aspectual reference, respectively. ${ }^{10,11}$

a. *Kòfí sèlé $\mathbf{l \varepsilon}$. Kofi swim DET intended: 'Kofi swam.'

b. *Kòfí sèlè-ó $\quad l \varepsilon$. Kofi swim-IMPF DET intended: 'Kofi swims.'

a. Kòfí nì sèlé $\mathbf{l} \boldsymbol{\varepsilon}$.

Kofi PRT swim DET

'It is Kofi who swam.'

b. Kòfí nì sèlè-ó le.

Kofi PRT swim-IMPF DET

'It is Kofi who is swimming.'

Looking at its semantics, VP $l \varepsilon$ has the same properties as NP $l \varepsilon$; that is, it encodes the information that the discourse referent, an event in the case of VP $l \varepsilon$, is both familiar and unique in bearing the property in question. A piece of evidence that $l \varepsilon$ encodes familiarity also in the verbal domain comes from the contrast presented in (19). Whereas VP $l \varepsilon$ is acceptable in the context in which a swimming event was discussed before, it is unacceptable in the context in which the swimming event was not previously discussed:

(19) Kofi ni sele le.

Kofi PRT swim DET

'It is Kofi who swam.'

a. context: We didn't talk about swimming before. Suddenly, I have decided to tell my friend who was swimming yesterday. $\Rightarrow$ I cannot utter (19)

b. context: We talked about swimming before and we are arguing who swam yesterday. $\Rightarrow$ I can utter (19) in this context

9 Clefts in Ga are introduced by the particle nì. For analysis, see Renans 2016 and Renans to appear. 10 Note that clefts with the particle nì but without the final clausal particle $l \varepsilon$ are acceptable.

11 For the whole paradigm, see Renans 2016. 
As NP $l \varepsilon$, VP $l \varepsilon$ exhibits bridging uses of the definite determiner, in which the discourse referent is familiar due to the relation between the discourse referent picked up by $l \varepsilon$ and the antecedent event description. This is illustrated below with (20), in which there is a part-whole relation between the triathlon in the context and the swimming event in the target sentence:

context: There was a team-triathlon yesterday.

Kòfí nì sèlé $\mathbf{l} \boldsymbol{\varepsilon}$.

Kofi PRT swim DET

'It is Kofi who swam.'

Turning to the uniqueness inference, the fact that the definite determiner $l \varepsilon$ only attaches to the VP in cleft structures, introduced by the particle $n i$, poses challenges to tease apart the exhaustivity triggered by clefts and the uniqueness triggered by the definite determiner $l \varepsilon$. For illustration, consider (21):

context: John, Tom, and Maria are in the process of swimming.

\#John nì sèlè-ó $1 \varepsilon$.

John PRT Swim-IMPF DET

'It is John who is swimming.'

Since clefts give rise to an exhaustive interpretation of the pivot, i.e., that John and nobody else swam, the target sentence in (21) is infelicitous in the context in which additional people swam. Thus, examples like (21) do not provide any evidence regarding the semantics of $l \varepsilon$.

It seems that one should aim at finding contexts in which the exhaustivity effect triggered by the cleft structure does not interfere with the uniqueness effect triggered by $l \varepsilon$, i.e., contexts in which the same agent performs either one activity or more than one activity of the given kind. Importantly, whereas the cleft structure would be felicitous in both cases, VP $l \varepsilon$ would be felicitous in the former case but not in the latter one. It seems that these kinds of contexts are habitual vs. progressive aspectual contexts. It is predicted that VP $l \varepsilon$ should be unacceptable in habitual contexts in which, for example, Kofi swims regularly, and acceptable in progressive contexts in which there is an ongoing unique event of swimming by Kofi. And these predictions are borne out, as demonstrated in (1), repeated below in (22):

(22) Kòfí nì sèlè-ó $\quad \mathbf{l}$.

Kofi PRT swim-IMPF DET

'It is Kofi who is swimming.'

a. progressive context: Tom and his family (wife, two sons, and two daughters) are on the beach. Tom and his wife can see a swimming child.

$\Rightarrow$ Tom can utter (22) in this context 
A cross-categorial definite determiner

b. habitual context: Tom's youngest son and daughters do not like swimming and they do not do it, but his oldest son, Kofi, loves swimming and he does it regularly. $\Rightarrow$ Tom cannot utter (22) in this context

To conclude this section, it was shown that both in the nominal and the verbal domain the definite determiner $l \varepsilon$ encodes the information that a discourse referent is familiar and unique in bearing the property in question, which is typical for definite determiners in a cross-linguistic perspective. A formal semantic analysis of a cross-categorial $l \varepsilon$ is given in the next section.

\section{Analysis}

Various proposals haven been made to model the semantics of definite determiners, e.g., Frege (1892); Russell (1905); Heim (1982); Roberts (2003); Elbourne (2005); Schwarz (2009); Neale (2004), among many others. I propose formalizing the familiarity and uniqueness of $l \varepsilon$ in Elbourne's (2005) system, extending his analysis to the VP domain.

Elbourne (2005) argues that definite determiners, at least in English, take two arguments, i.e., an NP and a covert pronominal index of type $\langle e, t\rangle .^{12,13}$

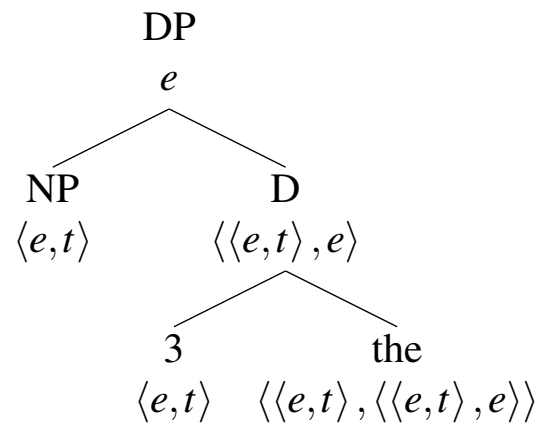

The index can be either bound or interpreted with respect to the assignment function $g$ which maps variables to familiar entities. With the latter, the definite description obtains a referential interpretation and it does not give rise to the inference that the NP is unique. For example, (24) says that there is a unique murderer such that the murderer is $g(3)$, but crucially it does not say that there is a unique murderer in general.

12 See Elbourne 2013 for a competing view that the English definite determiner the takes two arguments, i.e., an NP and a situation but not an index.

13 Following Elbourne (2005), Schwarz (2009) and Arkoh \& Matthewson (2013) argue that German strong definite determiners and the Akan definite determiner $n \mho$, respectively, also take an NP and a covert pronominal index as arguments. 
$\llbracket[[$ the 3$]$ murderer $] \rrbracket^{g}=$ the unique individual $x$ such that $x$ is a murderer and $x=g(3)$

(Elbourne 2005: 154)

In order to neutralize the referential interpretation effect of interpreting the covert pronominal index with respect to the assignment function, Elbourne (2005) introduces a special dummy index 0 , interpreted as $\lambda x: x_{e} \cdot x_{e}$. Its presence in the structure triggers a unique, attributive, i.e., not referential, interpretation of the NP, as illustrated in (25):

(25) $\quad \llbracket[[$ the 0$]$ murderer $] \rrbracket^{g}=$ the unique individual $x$ such that $x$ is a murderer (Elbourne 2005: 154)

Turning to $\mathrm{Ga}$, I claim that the definite determiner $l \varepsilon$ also takes two arguments: the NP and the pronominal index, which I formally analyze as a variable of type $e .^{14}$ The lexical entry for $l \varepsilon$ is given in (26):

$$
\llbracket 1 \varepsilon \rrbracket=\lambda y \cdot \lambda P: \exists ! x[P(x) \wedge x=y] . l x[P(x) \wedge x=y] \quad \text { [to be revised] }
$$

Moreover, following Musan (1995); Büring (2004); Keshet (2008); Schwarz (2009) and Elbourne (2013), I claim that definite determiners introduce situation pronouns to the syntax:

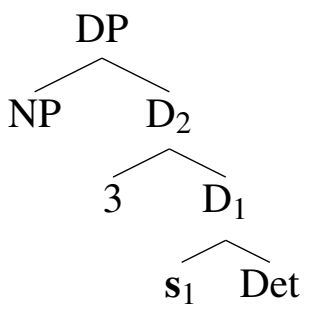

The variable $s$ is a syntactically represented situation pronoun introducing the situation with reference to which the NP denotation is interpreted. The index 3 is an additional pronominal argument taken by the definite determiner which is mapped by the assignment function to a familiar entity, as discussed above.

Since $l \varepsilon$ is a strong determiner, I claim that it also introduces a situation pronoun:

$$
\llbracket 1 \varepsilon \rrbracket=\lambda s . \lambda y . \lambda P: \exists ! x[x \text { is in } s \wedge P(x) \wedge x=y] . \iota x[x \text { is in } s \wedge P(x) \wedge x=y] \text { [final] }
$$

For illustration, the structure of wolo le ('the book') is presented in (29) and its derivation in (30): ${ }^{15,16}$

14 In this respect, I am following Schwarz's (2009) and Arkoh \& Matthewson's (2013) analyses in which the pronominal index is also of type $e$.

15 For presentational reasons, I omit the presupposed material.

16 Note that all pronominal elements receive their value via the assignment function. However, in order to increase the readability of the formulas, I do not mark it. The same holds for the derivation in (32). 
A cross-categorial definite determiner

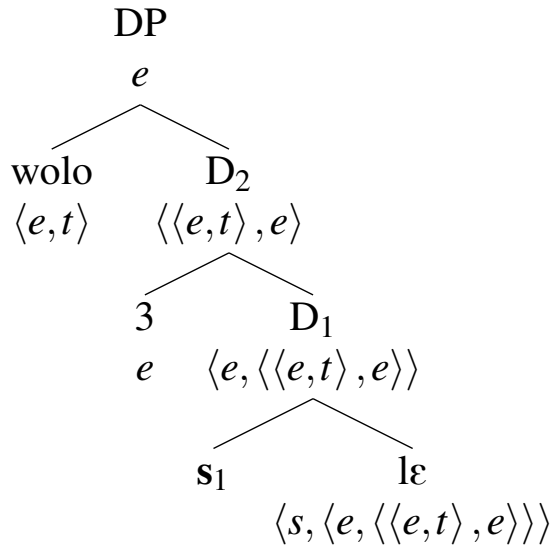

(30)

a. $\llbracket \mathrm{D}_{1} \rrbracket^{g}=\lambda y \cdot \lambda P . t x\left[x\right.$ is in $\left.s_{1} \wedge P(x) \wedge x=y\right]$

b. $\llbracket \mathrm{D}_{2} \rrbracket^{g}=\lambda y \cdot \lambda P . \ln \left[x\right.$ is in $\left.s_{1} \wedge P(x) \wedge x=y\right](g(3))$ $=\lambda P .1 x\left[x\right.$ is in $\left.s_{1} \wedge P(x) \wedge x=g(3)\right]$

c. $\llbracket \mathrm{DP} \rrbracket^{g}=\llbracket \mathrm{D}_{2} \rrbracket^{g}\left(\llbracket\right.$ wolo $\left.\rrbracket^{g}\right)=\imath x\left[x\right.$ is in $s_{1} \wedge$ wolo $\left.(x) \wedge x=g(3)\right]$

$\approx$ the unique individual $x$ such that $x$ is in the situation $s_{1}$ and $x$ is a book and $x$ is identical to $g(3)$

This analysis can account for the data presented in Section (3). The assignment function maps the covert index to familiar entities and thus it accounts for familiar uses of $l \varepsilon$. In addition, the data presented in Section 3 suggest that $l \varepsilon$ never triggers the interpretation that a discourse referent is unique in general but that a familiar discourse referent is unique in bearing the property in question. Therefore, I do not assume any special index which would neutralize the interpretive effects of analyzing the covert index with respect to the assignment function.

I argue that VP $l \varepsilon$ has the same semantics as NP $l \varepsilon$ and therefore I propose the same lexical entry for both of them. When $l \varepsilon$ attaches to the VP, it takes a property (a set of events) and says that there is a unique familiar event which has this property. As an example, the structure of sele le ('the swimming event') is given in (31) and its derivation in (32): ${ }^{17}$

17 The structure in (31) is unusual in that $\mathrm{D}$ takes $\mathrm{vP}$ as its argument and it does not project its properties. It might be that both NP $l \varepsilon$ and VP $l \varepsilon$ have the same semantics, but they are not of the same syntactic category. For presentational reasons, however, I am labeling VP $l \varepsilon$ and NP $l \varepsilon$ in a uniform way. A more detailed explication of this issue has to await future research. 


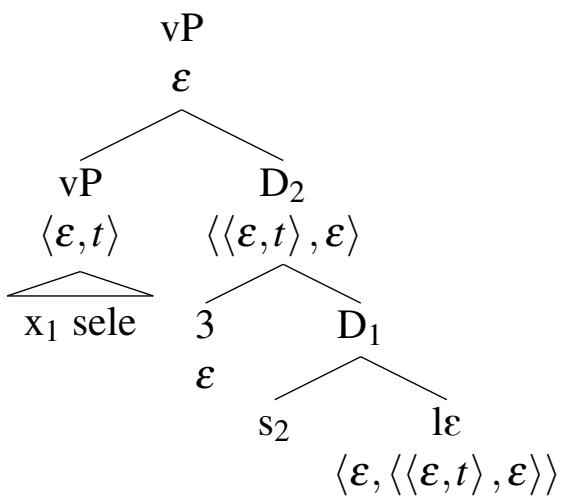

(32)

a. $\llbracket \mathrm{D}_{2} \rrbracket^{g}=\lambda P . l e\left[e\right.$ is in $\left.s_{1} \wedge P(e) \wedge e=g(3)\right]$

b. $\llbracket \mathrm{vP} \rrbracket^{g}=\lambda e \cdot \operatorname{swim}(e) \wedge A g(e)=x_{1}$

c. $\llbracket \mathrm{VP} \rrbracket^{g}=\llbracket \mathrm{D} \rrbracket^{g}(\llbracket \mathrm{vP} \rrbracket)$

$=\left[\lambda P .1 e\left[e\right.\right.$ is in $\left.\left.s_{1} \wedge P(e) \wedge e=g(3)\right]\right]\left(\lambda e . \operatorname{swim}(e) \wedge A g(e)=x_{1}\right)$

$=\imath e\left[e\right.$ is in $\left.s_{1} \wedge \operatorname{swim}(e) \wedge A g(e)=x_{1} \wedge e=g(3)\right]$

$\approx$ the unique event $e$ such that $e$ is in $s_{1}$ and $e$ is a swimming event, whose agent is $x_{1}$ and $e$ is $g(3)$

The last question that must be answered is why VP $l \varepsilon$ is only acceptable in clefted sentences. I argue that it is an effect of Maximize Presupposition (Heim 1991):

(33) Maximize presupposition: Among a set of alternatives, use the felicitous sentence with the strongest presupposition.

(Chemla 2008: 142)

Now, consider two alternative constructions in (34):

a. Kofi ni sele-J $1 \varepsilon$.

Kofi PRT swim-IMPF DET

'It is Kofi who is swimming'

b. \#Kofi sele-э le.

Importantly, events are instantiated in worlds by individuals. Conceptually, while it is impossible to identify a swimming event without knowing its agent(s), one can easily identify a swimming event by Kofi. However, if Bill is swimming as well, then it is not an event of swimming by Kofi but an event of swimming by Kofi and Bill. Now, the sentence in (34a) triggers a stronger presupposition than (34b); i.e., it triggers the exhaustive interpretation that Kofi and nobody else is swimming and thus it unambiguously identifies the swimming event. Therefore, due to Maximize Presupposition, (34b) becomes unacceptable. 
A cross-categorial definite determiner

\section{Consequences of the analysis: Progressive aspectual reference, events not- instantiated at the topic time, and evidentiality}

This analysis of the definite determiner $l \varepsilon$ predicts its interaction with the aspectual and evidential interpretation of the sentence when $l \varepsilon$ is attached to a VP, which are discussed below.

\subsection{Progressive aspectual reference and events non-instantiated at the topic time}

Imperfective aspect, marked by the suffix - $\supset$ in $\mathrm{Ga}$, entails the information that the topic time is included in the running time of the event:

$\llbracket-\supset \rrbracket=\lambda P_{\langle\varepsilon, t\rangle} \cdot \lambda t_{i} \cdot \exists e[t \subseteq \tau(e) \wedge P(e)] \approx$ there is such an event that the contextually given topic time is included in the running time of the event

Now, if $l \varepsilon$ conveys the meaning that there is a unique event in the VP denotation, an imperfective sentence with $V P l \varepsilon$ should necessarily obtain a progressive interpretation. This prediction is borne out, as it was shown in (1), repeated below in (36). I call this structure the analytic progressive. Note also that the same sentence without the VP $l \varepsilon$ is acceptable in the habitual context in (36a) but not in the progressive context in (36b). ${ }^{18}$

Kòfí nì sèlè-ó $\quad l \varepsilon$.

Kofi PRT Swim-IMPF DET

'It is Kofi who is swimming.'

a. progressive context: Tom and his family (wife, two sons, and two daughters) are on the beach. Tom and his wife can see a swimming child. $\Rightarrow(36)$ is acceptable in this context

b. habitual context: Tom's two sons and daughters do not like swimming and they do not do it, but his oldest son, Kofi, loves swimming and he does it regularly. $\Rightarrow(36)$ is unacceptable in this context

In addition, the interpretation of the analytic progressive, due to the presence of $l \varepsilon$, among others, is restricted to the unique event which is ongoing at the topic time. Therefore, it is predicted to be unacceptable in contexts in which the event, even though it might be ongoing, is not actually instantiated at the topic time, and

18 Note, however, that I argue in Renans 2016 that the invariable progressive interpretation conveyed by the analytic progressive in $\mathrm{Ga}$ is not solely caused by the interaction between the imperfective aspect and the definite determiner $l \varepsilon$ but by the interaction between the two aforementioned elements and the notion of exemplification (Kratzer 2007; Schwarz 2009) induced by the particle $n i$. 
this prediction is borne out. Consider (37). It is unacceptable, because the event of reading Harry Potter by John is not an ongoing, actual event. The topic time, which in the case of (37) coincides with the utterance time, cannot be included in the running time of the event of John reading Harry Potter, because at the topic time of (37), John is not reading anything but running.

(37) Tom and John are jogging. They are talking about books. Tom asks John which books he is reading. John replies:

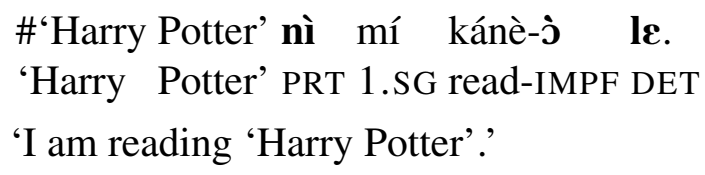

\subsection{Evidentiality}

The fact that the definite determiner $l \varepsilon$ encodes the information that a discourse referent, an event in the verbal domain, is not only unique in bearing the property in question but also familiar leads to predictions concerning the evidential interpretation of the sentences. In particular, it predicts VP $l \varepsilon$ to be only acceptable in contexts in which the speaker is familiar with the event, which in the case of progressive contexts would mean that the speaker has direct access to the event.

In Section 2, I presented Roberts's (2003) taxonomy of familiarity. She claims that a discourse referent is familiar if it is introduced by preceding linguistic material or it is salient in the utterance situation. In the analytic progressive an event is actually ongoing at the utterance time. Now, if the speaker got third-hand information that for example Kofi is swimming, i.e, the event was introduced by the linguistic material, she is familiar with the event. However, the speaker cannot be sure whether Kofi is still in the process of swimming at the time of speaking, which is required by the analytic progressive. It predicts that even though an event for which the speaker has reportative evidence is familiar, since it might not be ongoing at the utterance time, it is not sufficient for the felicitous use of sentences with the analytic progressive form. Therefore, the prediction is that the interpretation of the analytic progressive with the definite determiner $l \varepsilon$ is restricted to the events that the speaker has direct evidence for. As demonstrated in (1), repeated below in (38), this prediction is borne out:

(38) Kòfí nì sèlè-ó le.

Kofi PRT swim-IMPF DET

intended: 'It is Kofi who is swimming.'

a. direct evidence context: Tom and his family (wife, two sons, and two daughters) are on the beach. Tom can see that his one son and two daughters 
A cross-categorial definite determiner

are playing with sand and his oldest son, Kofi, is swimming.

$\Rightarrow$ Tom can utter (38) in this context

b. indirect evidence context: The same as before but this time Tom cannot see his oldest son, but the younger one told him that he was in the process of swimming.

$\Rightarrow$ Tom cannot utter (38) in this context

To sum up, in this section I have identified several consequences of the proposed analysis of the VP $l \varepsilon$ for the aspectual and evidential interpretation of the sentence, especially with the imperfective aspectual form. The question that arises immediately is whether the same interactions arise in other languages with definite descriptions of events or whether it is subject to cross-linguistic variation caused by the differences in the semantics of definite determiners across languages, which should be answered in the course of future research.

\section{Outlook}

As already demonstrated in Section 2, there are ways of conveying a definite interpretation in $\mathrm{Ga}$ other than using the definite determiner $l \varepsilon$. For example, one can use another definite determiner, namely $n \varepsilon \varepsilon$.

Interestingly, the definite determiner $n \varepsilon \varepsilon$ has a more restricted distribution in comparison to the definite determiner $l \varepsilon$. For example, whereas $l \varepsilon$ is acceptable in both contexts presented in (39), $n \varepsilon \varepsilon$ is only acceptable in the context of (39b), in which both the speaker and the hearer know about the discourse referent picked up by $n \varepsilon \varepsilon$ :

Nàrdù kè dùàdé néć ní yóo kèỳtéý le mlì a-bà.

Nardu bring. 1 cassava DET REL BE basket DET inside IMP-bring2

'Nardu, bring the cassava that is in the basket.'

a. Nardu visits her friend Ama. Ama is cooking banku and she needs more cassava. The cassava is in the basket but Nardu does not know about it. Also, they didn't talk about the cassava before.

$\Rightarrow$ Ama cannot utter (39)

b. The same as before but this time Nardu knows about the cassava.

$\Rightarrow$ Ama can utter (39)

Interestingly, as in the case of $l \varepsilon, n \varepsilon \varepsilon$ shows the same semantic properties in the nominal and the verbal domain. The same as $l \varepsilon, n \varepsilon \varepsilon$ interacts with the aspectual interpretation of the sentence leading to a progressive interpretation of the sentences with verbs conveying an imperfective aspectual interpretation. Moreover, same as 
$l \varepsilon$, VP $n \varepsilon \varepsilon$ also requires a direct evidential context. However, unlike with $l \varepsilon$, in the case of sentences with $n \varepsilon \varepsilon$ both the speaker and the hearer must have direct access

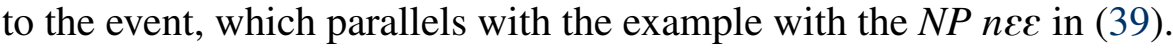

(40) Kòfí nì sèlè-ò néć.

Kofi PRT swim-IMPF DET

'It is Kofi who is swimming.'

a. Tom and his family (wife, 2 sons, and 2 daughters) are on the beach. Tom can see that Kofi is swimming.

$\Rightarrow$ Tom can say (40) to his wife

b. Tom and his children are on the beach. Tom can see that Kofi is swimming. He is talking to his wife over the phone.

$\Rightarrow$ Tom cannot say (40) to his wife

It seems that the differences in the semantics of $l \varepsilon$ and $n \varepsilon \varepsilon$ can be formally captured by different presuppositional conditions imposed on the assignment function $g$ (see the lexical entry for $l \varepsilon$ given in (26)). However, the full account of the definiteness system in $\mathrm{Ga}$ has to await another occasion.

\section{Summary}

In the paper, I presented empirical evidence that $l \varepsilon$ is an overt cross-categorial definite determiner that attaches to both NPs and VPs. In addition, $l \varepsilon$ shows the same semantic properties in both domains: it encodes the information that a discourse referent picked up by $l \varepsilon$ is both familiar and unique in bearing the property in question. This view predicts the interaction of $l \varepsilon$ with the aspectual and evidential interpretation conveyed by sentences with VP $l \varepsilon$, and these predictions are borne out. Importantly, the data from Ga raise the question of the existence of overt or covert definite determiners on events in other languages in particular and the ways the information about the definite events is conveyed in a cross-linguistic perspective in general.

\section{References}

Arkoh, Ruby \& Lisa Matthewson. 2013. A familiar definite article in Akan. Lingua 123. 1-30. doi:http://dx.doi.org/10.1016/j.lingua.2012.09.012.

Baker, Mark \& Lisa Travis. 1997. Mood as verbal definiteness in a 'tenseless' language. Natural Language Semantics 5(3). 213-269.

Barlew, Jefferson. 2014. Salience, uniqueness, and the definite determiner -tè in Bulu. In Todd Snider, Sarah D’Antonio \& Mira Weigand (eds.), Seman- 
A cross-categorial definite determiner

tics and Linguistic Theory (SALT) 24, 619-639. LSA and CLC Publications. doi:http://dx.doi.org/10.3765/salt.v24i0.2992.

Büring, Daniel. 2004. Crossover situations. Natural Language Semantics 12(1). 23-62. doi:http://dx.doi.org/10.1023/b:nals.0000011144.81075.a8.

Chemla, Emmanuel. 2008. An epistemic step for anti-presuppositions. Journal of Semantics 25(2). 141-173. doi:http://dx.doi.org/10.1093/jos/ffm017.

Coppock, Elizabeth \& David Beaver. 2015. Definiteness and determinacy. Linguistics and Philosophy 38(5). 377-435. doi:http://dx.doi.org/10.1007/s10988-0159178-8.

Dakubu, Mary Esther Kropp. 1992. Contrast in context: Topic, focus, and definiteness in Ga. Journal of West African Languages 22(2). 3-16.

Dakubu, Mary Esther Kropp. 2005. The syntax of focus in Ga and the significance of related constructions. In The Conference on Focus in African Languages, Humboldt University, Berlin.

Elbourne, Paul. 2005. Situations and Individuals. MIT Press.

Elbourne, Paul. 2013. Definite Descriptions. Oxford University Press.

Frege, Gottlob. 1892. Über Sinn und Bedeutung. Zeitschrift für Philosophie und Philosophische Kritik 100. 25-50.

Grubic, Mira. 2015. Focus and alternative sensitivity in Ngamo (West Chadic): Universität Potsdam $\mathrm{PhD}$ dissertation.

Heim, Irene. 1982. The semantics of definite and indefinite noun phrases: University of Massachusetts, Amherst PhD dissertation.

Heim, Irene. 1991. Artikel und Definitheit. In Arnim von Stechow \& Dieter Wunderlich (eds.), Semantik: ein internationales Handbuch der Zeitgenössischen Forschung, 487-535. de Gruyter, Berlin.

Heim, Irene \& Angelika Kratzer. 1998. Semantics in Generative Grammar. Oxford: Blackwell.

Keshet, Ezre. 2008. Good intensions: Paving two roads to a theory of the de re/ de dicto distinction: Massachusetts Institute of Technology $\mathrm{PhD}$ dissertation.

Kratzer, Angelika. 2007. Situations in natural language semantics. In Edward N. Zalta (ed.), The Stanford Encyclopedia of Philosophy, http://plato.stanford.edu/ archives/spr2014/entries/situations-semantics/.

Larson, Richard K. 2003. Event descriptions in Fòn and Haitian Creole. In Dany Adon (ed.), Recent development in Creole Studies, 67-90. Walter de Gruyter.

Matthewson, Lisa. 2004. On the methodology of semantic fieldwork. International Journal of American Linguistics 70(4). 369-415.

Musan, Renate. 1995. On the temporal interpretation of nouns phrases: Massachusetts Institute of Technology $\mathrm{PhD}$ dissertation.

Neale, Stephen. 2004. This, that, and the other. In Marga Reimer \& Anne Bazuidenhout (eds.), Descriptions and beyond, 68-182. Oxford University Press. 
Renans, Agata. 2015. Three types of indefinites: Evidence from Ga (Kwa). In Thomas Brochhagen, Floris Roelofsen \& Nadine Theiler (eds.), 20th Amsterdam Colloquium, 343-352.

Renans, Agata. 2016. Exhaustivity. on exclusive particles, clefts, and progressive aspect in $\mathrm{Ga}$ (Kwa): Universität Potsdam $\mathrm{PhD}$ dissertation.

Renans, Agata. to appear. Modeling the exhaustivity inference of clefts: Evidence from Ga (Kwa). In Polina Berezovskaya, Nadine Bade \& Anthea Schöller (eds.), Sinn und Bedeutung (SuB) 20, .

Roberts, Craige. 2003. Uniqueness and definite noun phrases. Linguistics and Philosophy 26(3). 287-350.

Russell, Bertrand. 1905. On denoting. Mind 14(56). 479-493.

Schwarz, Florian. 2009. Two types of definites in natural language: University of Massachusetts, Amherst PhD dissertation.

Szabó, Zoltán Gendler. 2000. Descriptions and uniqueness. Philosophical Studies 101(1). 29-57.

Szabó, Zoltán Gendler. 2003. Definite descriptions without uniqueness: A reply to Abbott. Philosophical Studies 114(3). 279-297.

\author{
Agata Renans \\ Universität Potsdam \\ Department Linguistik \\ Karl-Liebknecht-Straße 24-25 \\ DE-14476 Potsdam \\ renans@uni-potsdam.de
}

